\title{
AVALIAÇÃO MICROBIOLÓGICA E FÍSICO-QUÍMICA DE DOCE DE LEITE E REQUEIJÃO PRODUZIDOS COM LEITE DE BUFÁLA NA ILHA DO MARAJÓ-PA
}

\author{
CONSUELO L. SOUSA * \\ ELISA CRISTINA A. NEVES * \\ CÉSAR AUGUSTO A. CARNEIRO ** \\ JOVANA B. DE FARIAS ** \\ MARIA REGINA S. PEIXOTO ***
}

\begin{abstract}
Avaliou-se a qualidade microbiológica e físico-química de doces de leite e requeijões produzidos, na llha do Marajó PA (Brasil), com leite de búfala. Não foi detectada a presença de Salmonellas e Staphylococcus aureus nas amostras dos produtos analisados e os resultados obtidos para contagem de bactérias mesófilas e bolores e leveduras para o doce de leite demonstraram boas condições higiênicosanitárias do produto. Porém, 28,60\% das amostras de requeijão apresentaram condições higiênico-sanitárias insatisfatórias, sendo 14,26\% consideradas impróprias para o consumo humano. Na caracterização físico-química, $83,34 \%$ das amostras de doce de leite apresentaram teores de gordura superiores ao padrão $(6,0$ a 9,0\%) e uma amostra mostrou-se acima do limite permitido (máx. 30\%) para umidade. Verificou-se que $100 \%$ das amostras de requeijão apresentaram teores de proteínas (mín. 5\%) e umidade (máx. $60 \%$ ) de acordo com os padrões e apenas $14,86 \%$ enquadraram-se no padrão para gordura no extrato seco total (45 a 54,9\%). Esses resultados sugerem que o requeijão de leite de búfala pode estar sendo produzido a partir de matérias-primas de qualidade microbiológica inadequada ou o produto está sendo contaminado durante a produção, o transporte, o armazenamento ou a comercialização.
\end{abstract}

PALAVRAS-CHAVE: DOCE DE LEITE; QUEIJO MARAJOARA; QUEIJO-QUALIDADE MICROBIOLÓGICA; QUEIJO-CARACTERIZAÇÃO FÍSICO-QUÍMICA.

* Professor, M.Sc., Departamento de Engenharia Química, Universidade Federal do Pará (UFPA), Belém, PA. (e-mail: sousa@ufpa.br).

** Alunos de Graduação, Departamento de Engenharia Química, UFPA, Belém, PA.

*** Pesquisadora, Departamento de Engenharia Química da UFPA, Belém, PA. 


\section{INTRODUÇÃO}

O rebanho bubalino brasileiro aumentou cerca de $12,7 \%$ ao ano, na década de 80 , tornando-se alternativa à pecuária tradicional. O leite de búfala apresenta elevado valor nutricional, altos níveis de gordura, proteínas e minerais sendo importante para o consumo in natura e como matériaprima na elaboração de produtos lácteos (MANO FILHO, 1991).

No Pará, principalmente na ilha de Marajó e nas várzeas do rio Amazonas, a pecuária apresenta grande importância econômica, registrando-se aumento considerável na produção leiteira de bubalinos. Entretanto, não há aproveitamento satisfatório dessa matéria-prima, mesmo na região que concentra o maior rebanho bubalino brasileiro (ANUÁRIO, 1997).

A história do búfalo doméstico (Bubalus bubalis) teve sua origem na Ásia. Essa espécie foi levada para África, mais tarde para a Europa e depois para a América. No Brasil, foi introduzida em 1895, na Ilha de Marajó, Pará. Com o passar dos anos, essa espécie animal constituiu-se em importante alternativa de para produção de leite e derivados, principalmente para suprir as demandas dos países em desenvolvimento (MOURA CARVALHO et al., 1997; GILL, 1986).

O leite bubalino, devido suas características peculiares, é matéria-prima ideal para elaboração de diversos produtos. Seu rendimento industrial, na elaboração de laticínios é $40 \%$ superior ao leite bovino. Apresenta 33\% menos colesterol e $48 \%$ a mais de proteína, 59\% de cálcio e $47 \%$ de fósforo que o leite bovino. Contendo maior teor de gordura são necessários apenas 14 litros de leite de búfala para produzir $1 \mathrm{~kg}$ de manteiga, enquanto que o leite de vaca bovina exige mais de 20 litros (HÜHN et al., 1986). No Brasil, alguns laticínios elaboram vários derivados desse leite, gerando produtos reconhecidos por sua alta qualidade e sabor especial (GUINART et al., 1996).

A llha do Marajó, apesar de ser o maior centro de bubalinocultura do Brasil, enfrenta dificuldades para aproveitar o leite devido sua distância dos centros consumidores. Tal fato, implica no aproveitamento do leite para elaboração de produtos com maior período de conservação.

O desenvolvimento tecnológico introduziu novo conceito de inocuidade dos alimentos, que inclui aspectos que vão desde a fazenda, em que são produzidos os animais até o consumidor. Essa cadeia envolve: autoridades governamentais, produtores agropecuários, transportadores de matéria- 
prima e de produtos industrializados, indústrias processadoras, atacadistas, varejistas, universidades, empresas de comunicação social e o consumidor. São todos responsáveis pela manutenção da inocuidade dos alimentos, evitando que se transformem em fontes de doenças (SILVA JR., 1996).

Vários produtos elaborados com leite de búfala já foram devolvidos (FERRARA e INTRIERE, 1975; HÜHN et al., 1986; HÜHN et al., 1991; VERRUMA et al., 1993; BERNARDI, et al., 2000). O doce de leite e o requeijão (denominado de requeijão marajoara) são os produtos derivados mais comumente produzidos na llha do Marajó, com grande aceitação no mercado local e na capital do Estado. São elaborados de forma artesanal e muitas vezes em condições inadequadas, havendo poucas pesquisas sobre as características microbiológicas e a vida útil desses derivados.

O presente trabalho teve como objetivo avaliar a qualidade microbiológica e físico-química de doce de leite e requeijão, produzidos com leite de búfala na llha do Marajó - PA.

\section{MATERIAL E MÉTODOS}

\subsection{MATERIAL}

Foram adquiridas no comércio varejista das cidades de Soure e Salvaterra, na llha de Marajó - PA, 18 amostras de doces de leite e 7 amostras de requeijão ou queijo tipo marajoara, de diferentes marcas, elaborados com leite de búfala de maneira artesanal na própria região.

As amostras de requeijão foram armazenadas e transportadas em recipientes térmicos até os Laboratórios de Análises Microbiológicas e Físico-químicas do Departamento de Engenharia Química da Universidade Federal do Pará (DEQ/CT/UFPA). O tempo máximo decorrido entre as coletas de amostras e as análises foi de 24 horas.

\subsection{MÉTODOS}

\subsubsection{Análises microbiológicas}

Como não existe legislação específica para leite e derivados bubalinos, todas as amostras foram analisadas quanto aos parâmetros exigidos pela 
legislação vigente para doce de leite e requeijão obtidos com leite bovino (BRASIL,1997). Além das análises legais exigidas foram efetuadas as contagens de coliformes totais, bactérias mesófilas em placas e bolores e leveduras para o doce de leite; coliformes fecais e totais e Staphylococus aureus para o requeijão. Todas as análises seguiram metodologias descritas no Compendium of Methods for the Microbiological of Foods (VANDERZANT e SPLITTSTOESSER, 1992).

\section{- Preparo das amostras e suas diluições}

Foram retiradas, assepticamente, duas porções de $25 \mathrm{~g}$ de cada amostra, as quais foram homogeneizadas por 30 segundos em "Stomacher " (Lab Blender 400) com $225 \mathrm{~mL}$ de solução salina peptonada a 0,1\% (SSP). Uma delas foi incubada a $35-37^{\circ} \mathrm{C}$ por 24 horas para pré-enriquecimento de Salmonella. Da outra porção foram realizadas diluições decimais até $10^{-4}$ para uso nas demais análises.

\section{- Contagem de coliformes totais e fecais}

Foi utilizada a técnica de tubos múltiplos, com série de três tubos em cada diluição $(0,1 ; 0,01 ; 0,001)$. Empregou-se como meio presuntivo o caldo lauril sulfato triptose com incubação a $35^{\circ} \mathrm{C} / 48$ horas. No teste confirmativo foi utilizado o caldo lactose verde brilhante bile $2 \%$ para coliformes totais, com incubação a $35^{\circ} \mathrm{C} / 24-48$ horas, e caldo EC para coliformes fecais com incubação a $44,5^{\circ} \mathrm{C}$ em banho-maria por 24 horas. O Número Mais Provável (NMP) de coliformes totais e fecais foi determinado com auxílio da Tabela de Hoskins.

\section{- Contagem de bactérias aeróbias mesófilas}

Transferiu-se $1 \mathrm{~mL}$ de cada diluição para placas de Petri estéreis em duplicata. Empregou-se a técnica de semeadura em profundidade, utilizando o ágar plate count, com incubação a $37^{\circ} \mathrm{C}$ por 48 horas, sendo os resultados expressos em UFC/g ou mL.

\section{- Contagem de bolores e leveduras}

Transferiu-se $1 \mathrm{~mL}$ de cada diluição para placas de Petri estéreis em duplicata. Empregou-se a técnica de semeadura em profundidade, utilizando o meio ágar batata dextrose acidificado com ácido tartárico a $10 \%$ com incubação a $22-25^{\circ} \mathrm{C}$ durante 5 dias (resultados expressos em UFC/g). 


\section{- Contagem de Staphylococcus Aureus}

Foram inoculadas alíquotas de $0,1 \mathrm{~mL}$ de diferentes diluições sobre a superfície do ágar Baird - Park em duplicata. Após incubação a $37^{\circ} \mathrm{C}$ por 48 horas, as colônias características de $S$. aureus foram enumeradas e submetidas aos testes de produção de catalase, coagulase e termonuclease para confirmação. Os resultados foram expressos em UFC/g.

\section{- Pesquisa de Salmonella sp}

Após o pré-enriquecimento em SSP, $1 \mathrm{~mL}$ de cada cultivo foi transferido para $10 \mathrm{~mL}$ de caldo selenito-cistina e $1,0 \mathrm{~mL}$ para $10 \mathrm{~mL}$ de caldo tetrationato e incubadas a $37^{\circ} \mathrm{C}$ por 24 horas. Para o isolamento de colônias foi realizada a semeadura em superfície em ágar SS (Salmonella -Shiguella) e BGA (ágar verde brilhante) com incubação a $37^{\circ} \mathrm{C}$ por 24 horas. As colônias suspeitas foram confirmadas mediante testes bioquímicos (TSI, LIA, Caldo Uréia, meio IAL, Caldo Malonato Fenil Alanina) e sorológicos (soro 0 e $\mathrm{H}$ polivalentes).

\subsubsection{Análises Físico-Químicas}

Os parâmetros físico-químicos analisados nas amostras de doce de leite foram acidez, umidade, gordura, proteína, cinzas e carboidratos. No requeijão foram realizadas as mesmas análises, além de cloreto e valor calórico. Todas as análises foram efetuadas de acordo com as Normas Analíticas do INSTITUTO ADOLFO LUTZ (1985).

\section{RESULTADOS E DISCUSSÃO}

\subsection{DOCE DE LEITE DE BÚFALA}

\subsubsection{Análises microbiológicas}

Em nenhuma das 18 amostras de doce de leite analisadas foi detectada a presença de coliformes totais, fecais e Salmonella. A presença de bolores e leveduras e bactérias aeróbias mesófilas foi detectada em 22,2\% e $27,8 \%$ das amostras, respectivamente. A contagem de bolores e leveduras variou de $<1,5 \times 10^{2}$ a $7,4 \times 10^{3}$ e a de bactérias aeróbias mesófilas em todas as amostras foi $<3 \times 10^{2}$. 
Observa-se pela Tabela 1, que apenas $11 \%$ das amostras apresentaram resultados superiores a $10^{3} \mathrm{UFC} / \mathrm{g}$ para bolores e leveduras. A contagem de bactérias mesófilas não ultrapassou a faixa de $10^{2}$. Os resultados obtidos demonstraram boas condições higiênico-sanitárias dos produtos.

\section{TABELA 1 - NÚMERO DE AMOSTRAS DE DOCES DE LEITE DE BÚFALA, POR FAIXA DE CONTAGEM DE UFC DE BOLORES E LEVEDURAS E BACTÉRIAS AERÓBIAS MESÓFILAS}

\begin{tabular}{|c|c|c|c|c|c|c|c|c|}
\hline \multirow[t]{3}{*}{ Determina I es } & \multicolumn{8}{|c|}{ Faixas de contagem (UFC/g) } \\
\hline & \multicolumn{2}{|c|}{$<10$} & \multicolumn{2}{|c|}{$10^{1}-10^{2}$} & \multirow{2}{*}{$\begin{array}{l}>10^{2} \\
\mathrm{~N}\end{array}$} & \multirow{2}{*}{$\begin{array}{l}10^{3} \\
\%\end{array}$} & \multirow{2}{*}{$\begin{array}{l}>10^{3} \\
\mathrm{~N}\end{array}$} & \multirow{2}{*}{$\begin{array}{l}10^{4} \\
\%\end{array}$} \\
\hline & $\mathrm{N}$ & $\%$ & $\mathrm{~N}$ & $\%$ & & & & \\
\hline Bolores e leveduras & 14 & 77,8 & 1 & 5,6 & 1 & 5,6 & 2 & 11,0 \\
\hline $\begin{array}{l}\text { BactØrias aer bias } \\
\text { mes filas }\end{array}$ & 13 & 72,2 & 5 & 27,8 & 0 & 0 & 0 & 0 \\
\hline
\end{tabular}

UFC = Unidade Formadora de Colônias.

\subsubsection{Análises físico-química de doces de leite}

Os resultados obtidos nas análises físico-químicas dos doces de leite estão apresentados na Tabela 2. Supõe-se que 16,66\% das amostras (3 amostras) tenham sido elaboradas com leite desnatado, pois apresentaram teor de $0 \%$ de gordura. As demais apresentaram teores de gordura superiores ao padrão (6,0 a 9,0\%), indicando tratar-se de leite integral. Tais resultados evidenciam ausência de padronização do leite de búfala utilizado na elaboração dos produtos.

Apenas uma amostra apresentou umidade acima do limite permitido (máx. $30 \%$ ), entretanto várias amostras mostraram teores muito baixos de umidade e altos teores de carboidratos. Tal fato poderia ocasionar cristalização da sacarose durante a armazenagem com alteração da textura do produto.

Todas as amostras apresentaram teor de proteínas superior ao mínimo (5\%) exigido pela legislação. 
TABELA 2 - RESULTADOS DAS ANÁLISES FÍSICO-QUÍMICAS DE DOCES DE LEITE DE BÚFALA - ILHA DO MARAJÓ - PA

\begin{tabular}{|c|c|c|c|c|c|c|}
\hline Amostras & $\begin{array}{c}\text { Acidez } \\
(\%)\end{array}$ & $\begin{array}{c}\text { Umidade } \\
(\%)\end{array}$ & $\begin{array}{c}\text { Cinzas } \\
(\%)\end{array}$ & $\begin{array}{c}\text { Gordura } \\
(\%)\end{array}$ & $\begin{array}{c}\text { Prote na } \\
(\%)\end{array}$ & $\begin{array}{c}\begin{array}{c}\text { Carboidratos } \\
(\%)\end{array} \\
\end{array}$ \\
\hline 1 & 4,60 & 9,20 & 1,43 & 12,64 & 8,90 & 67,83 \\
\hline 2 & 4,54 & 8,90 & 1,47 & 12,68 & 8,86 & 68,09 \\
\hline 3 & 4,57 & 9,90 & 1,56 & 12,47 & 8,87 & 67,20 \\
\hline 4 & 4,63 & 10,2 & 1,60 & 12,70 & 8,84 & 66.66 \\
\hline 5 & 4,50 & 9,60 & 1,48 & 12,78 & 8,88 & 67,26 \\
\hline 6 & 4,55 & 8,60 & 1,55 & 12,61 & 8,82 & 68,48 \\
\hline 7 & 4,53 & 9,70 & 1,59 & 12,75 & 8,81 & 67,15 \\
\hline 8 & 4,62 & 10,1 & 1,41 & 12,63 & 8,83 & 67,03 \\
\hline 9 & 4,64 & 9,40 & 1,52 & 12,71 & 8,85 & 67,52 \\
\hline 10 & 4,52 & 8,80 & 1,45 & 12,65 & 8,80 & 65,33 \\
\hline 11 & 0,39 & 19,15 & 1,87 & 13,0 & 7,93 & 58,05 \\
\hline 12 & 0,38 & 19,09 & 1,83 & 12,5 & 8,62 & 57,96 \\
\hline 13 & 0,43 & 18,95 & 1,83 & 13,5 & 8,61 & 57,11 \\
\hline 14 & 0,47 & 23,04 & 1,90 & 0,0 & 7,97 & 67,09 \\
\hline 15 & 0,50 & 27,83 & 1,85 & 0,0 & 7,81 & 62,51 \\
\hline 16 & 0,48 & 33,44 & 1,89 & 0,0 & 8,24 & 56,43 \\
\hline 17 & 0,56 & 26,85 & 2,01 & 14,0 & 10,0 & 47,14 \\
\hline 18 & 0,51 & 26,30 & 2,03 & 14,0 & 9,26 & 48,41 \\
\hline Padr ${ }^{a} 0^{*}$ & -- & M/区.30,0 & M/区 2,0 & 6,0 a 9,0 & M n. 5,0 & -- \\
\hline
\end{tabular}

* BRASIL, 1997.

\subsection{REQUEIJÃO DE LEITE DE BÚFALA}

\subsubsection{Análises microbiológicas do requeijão}

Não foi detectada a presença de Salmonella e Staphylococus aureus em nenhuma das amostras de requeijão analisadas (Tabela 3).

\section{TABELA 3 - RESULTADOS DAS ANÁLISES MICROBIOLÓGICAS DE REQUEIJÕES ELABORADOS COM LEITE DE BÚFALA - ILHA DE MARAJÓ - PA}

\begin{tabular}{|c|c|c|c|}
\hline Amostras & $\begin{array}{c}\text { Coliformes totais } \\
\text { NMP/g }\end{array}$ & $\begin{array}{c}\text { Coliformes fecais } \\
\text { NMP/g }\end{array}$ & $\begin{array}{c}\text { Bolores e leveduras } \\
\text { UFC/g }\end{array}$ \\
\hline 1 & $<3$ & $<3$ & $<10$ \\
\hline 2 & $<3$ & $<3$ & $2,3 \times 10^{2}$ \\
\hline 3 & $<3$ & $<3$ & $<1,5 \times 10^{2}$ \\
\hline 4 & 460 & 460 & $4,4 \times 10^{4}$ \\
\hline 5 & 4 & 4 & $4,8 \times 10^{3}$ \\
\hline 6 & 9 & $<3$ & $6,4 \times 10^{3}$ \\
\hline 7 & $<3$ & $<3$ & $<10$ \\
\hline $\mathrm{Padr}^{\mathrm{a}} \mathrm{O}^{*}$ & - & $\begin{array}{c}1 / \mathrm{g} \\
\text { (m/Aximo) }\end{array}$ & $\begin{array}{c}10^{3} \\
\text { (m/Eimo) }\end{array}$ \\
\hline
\end{tabular}

*BRASIL, 1997. 
Constatou-se a presença de coliformes totais em $42,8 \%$ (3) das amostras analisadas, com contagem variando de 4 a $460 \mathrm{NMP} / \mathrm{g}$. A presença de coliformes fecais foi detectada em $28,6 \%$ (2) das amostras, com resultados acima do limite estabelecido na legislação vigente (BRASIL,1997) para queijo fundido e requeijão (Tabela 3), demonstrando condições higiênicosanitárias insatisfatórias.

Bolores e leveduras foram encontrados em $71,4 \%$ (5) das amostras de requeijão, com contagens variando de $<1,5 \times 10^{2}$ a $4,4 \times 10^{4}$.

Das amostras analisadas $42,86 \%$ não se enquadraram nos padrões estabelecidos pela legislação, sendo que $28,60 \%$ encontravam-se em condições higiênico-sanitárias insatisfatórias e 14,26\% foram consideradas impróprias para o consumo.

\subsubsection{Análises físico-químicas do requeijão}

Todas as amostras enquadraram-se nos padrões oficiais para o produto em relação a umidade. Já para a gordura no extrato seco total apenas uma amostra (14,86\%) atendeu a legislação (Tabela 4).

\section{TABELA 4 - RESULTADOS DAS ANÁLISES FÍSICO-QUÍMICAS DOS REQUEIJÕES ELABORADOS COM LEITE DE BÚFALA - ILHA DO MARAJÓ - PA}

\begin{tabular}{|c|c|c|c|c|c|c|c|c|}
\hline Produtos & 1 & 2 & 3 & 4 & 5 & 6 & 7 & Padr ${ }^{a} O^{*}$ \\
\hline $\begin{array}{c}\text { Acidez } \\
(\% \text { ac. IAfico })\end{array}$ & 0,19 & 0,20 & 0,19 & 0,18 & 0,18 & 0,16 & 0,20 & \\
\hline Umidade $(\%)$ & 47,69 & 47,89 & 47,01 & 45,30 & 39,79 & 39,78 & 40,44 & $\mathrm{~m}$ Æx. $60 \%$ \\
\hline Gordura (\%) & 33,72 & 33,31 & 33,00 & 28.05 & 33,67 & 37,94 & 38,14 & \\
\hline $\begin{array}{c}\text { Gordura no } \\
\text { EST }(\%)\end{array}$ & 64,46 & 63,92 & 62,27 & 51,27 & 55,92 & 63,00 & 64,03 & $\begin{array}{c}45,0 \mathrm{a} \\
54,9\end{array}$ \\
\hline Prote nas (\%) & 15,90 & 15,61 & 16,16 & 21,86 & 22,13 & 19,91 & 19,04 & \\
\hline $\begin{array}{c}\text { Carboidratos } \\
(\%)\end{array}$ & 0,81 & 1,34 & 1,96 & 2,39 & 1,89 & 0,58 & 0,71 & \\
\hline Cinzas $(\%)$ & 1,88 & 1,88 & 1,88 & 2,40 & 2,52 & 1,79 & 1,67 & \\
\hline Cloreto $(\%)$ & 0,83 & 0,78 & 0,84 & 1,16 & 1,05 & 0,67 & 0,48 & \\
\hline Valor cal rico & 370 & 370 & 370 & 350 & 400 & 430 & 425 & \\
\hline
\end{tabular}

*BRASIL, 1997. 
Segundo LERAYER et al. (1998) não há diferenciação entre requeijão cremoso e de corte na legislação em relação a umidade e teor de gordura, sendo recomendado que o requeijão de corte apresente 48 a $54 \%$ de umidade e teor de gordura entre 24 e $32 \%$. Verificou-se que $100 \%$ das amostras analisada apresentaram teores de umidade e gordura inferiores e superiores ao indicado, respectivamente.

De acordo com a classificação do Regulamento Técnico de Identidade para Queijos (BRASIL, 1997), em relação ao conteúdo de matéria gorda no extrato seco, $71,4 \%$ das amostras de requeijão foram classificadas como extra gordas (por apresentarem teores superiores a $60 \%$ ) e $28,6 \%$ como gordas (faixa de $45 \%$ a $59,9 \%$ ).

\section{CONCLUSÃO}

Não foi detectada a presença de Salmonella e de Staphylococcus aureus em nenhuma das amostras de requeijão e de doce de leite analisadas.

Os resultados obtidos para contagem de bactérias mesófilas e bolores e leveduras para o doce de leite, elaborado com leite de búfala, evidenciaram boas condições higiênico-sanitárias do produto. Entretanto, 28,60\% das amostras de requeijão apresentaram condições higiênico-sanitárias insatisfatórias e 14,26\% mostraram-se impróprias para o consumo humano.

Das amostras de doce de leite, $16,66 \%$ estavam isentas de gordura e as demais com conteúdo superior ao padrão (6,0 a 9,0\%) indicando ausência de padronização do leite de búfala produzido na llha de Marajó. Apenas uma amostra apresentou umidade acima do padrão (máx. $30 \%)$.

Para o requeijão, $100 \%$ das amostras apresentaram teor de proteína superior ao mínimo (5\%) exigido pela legislação. Para umidade 100\% destas encontravam-se de acordo com o padrão e 14,86\% não atenderam ao padrão para gordura no extrato seco total (EST).

Os resultados obtidos sugerem que o requeijão elaborado com leite de búfala pode estar sendo produzido a partir de matérias-primas de qualidade microbiológica inadequada ou o produto está sendo contaminado durante a produção, o transporte, o armazenamento ou a comercialização. 


\begin{abstract}
MICROBIOLOGICAL AND PHYSICAL-CHEMISTRY EVALUATION OF SWEETENED MILK AND SPREAD CHEESE PRODUCED WITH BUFALLO'S MILK IN MARAJO ISLAND - PA

The microbiological and physical-chemistry quality of the Sweetened milk and the Spread cheese produced with Buffalo's milk, in Marajó Island - PA, were evaluated. It was not detected the presence of Salmonella and Staphylococcus aureus in samples of the analysed products and the results obtained for mesophilic bacteria, molds and yeast counting for sweetened milk showed good sanitary conditions of the product. However, $28,60 \%$ of the Spread cheese samples presented insatisfactories conditions and $14,26 \%$ were inappropriate for human consumption. At the physical-chemistry characterization, $83,34 \%$ of the Sweetened milk samples presented contents of fat superior to the pattern $(6,0$ a 9,0$)$, and about the humidity, just a sample was above the pattern (max.30\%). For the Spread cheese, it was verified that $100 \%$ of the samples presented contents of proteins ( $\min .5 \%$ ) and humidity (max.60\%) inside the pattern and only $14,86 \%$ were inside of the pattern for fat in total solids ( $45 \%$ to $54,9 \%)$. It may be inferred that Spread cheese produced with Buffalo's milk has been either with milk of inadequate sanitary conditions or contaminated during the process, transportation, storage and commercialization.
\end{abstract}

KEY WORDS: SWEETENED MILK; MARAJOARA'S CHEESE; CHEESEMICROBIOLOGICAL QUALITY; CHEESE-PHYSICAL-CHEMISTRY CHARACTERIZATION.

\title{
REFERÊNCIAS
}

1 ANUÁRIO estatístico da produção animal. São Paulo: Argos Comunicação, 1997.

2 BERNARDI, M.R.V.; DAMÁSIO, M.H.; VALLE, J.L.E.; OLIVEIRA, A.J. Elaboração do queijo mozarela de leite de búfala pelos métodos tradicional e da acidificação direta. Ciênc. Tecnol. Aliment., v.20, n.2, p. 138-144, 2000.

3 BRASIL. Ministério da Agricultura e do Abastecimento. Regulamentos técnicos de identidade e qualidade de leite e produtos lácteos. Brasília, 1997.

4 FERRARA, B.; INTRIERI, F. Características e emprego do leite de búfala. Zoootecnia, v.13, n.1, p. 25-50, 1975.

5 GILL, S.S. Effect of day and humid hot seasons on the reproduction and milk production of water buffalo (Bubalus bubalis). In: SIMPÓSIO DO TRÓPICO ÚMIDO, 1., 1984, Belém. Anais... Belém: EMBRAPACPATU, 1986. v. 5. p. 251-258. (Documentos, 36). 
6 GUINART, T.C. et al. Característica do leite de búfala e seus derivados. Leite e Derivados, n. 22, p. 16-20, maio/jun. 1996.

7 HÜHN, S.; LOURENÇO JUNIOR, J.B.; MOURA CARVALHO, L.O.D.; NASCIMENTO, C.N.B.; VIEIRA, L.C. Aproveitamento do leite de búfala em produtos derivados. In: SIMPÓSIO DO TRÓPICO ÚMIDO, 1., 1984, Belém. Anais... Belém: EMBRAPA/CPATU, 1986. v.5. p. 265-269. (Documentos, 36).

8 HÜHN, S.; LOURENÇO JUNIOR, J.B.; MOURA CARVALHO, L.O.D.; NASCIMENTO, C.N.B.; VIEIRA, L.C. Características, peculiaridades e tecnologia do leite de búfalas. Belém: EMBRAPA - CPATU, 1991. 51 p. (Documentos, 57).

9 INSTITUTO ADOLFO LUTZ. Normas analíticas do Instituto Adolfo Lutz. São Paulo, 1985.

10 INTERNATIONAL COMMISSION ON MICROBIOLOGICAL SPECIFICATIONS FOR FOODS. Microorganisms in foods. 1. Significance and methods of enumeration. $2^{\text {nd }} \mathrm{ed}$. Toronto, 1978. v. 1.

11 JAY, J.M. Modern food microbiology. $3^{\text {rd }}$ ed. New York: Van Nortran Reinhold, 1992.

12 LERAYER, A. et.al. Nova legislação (comentada) de produtos lácteos e de alimentos para fins especiais, diet, light e enriquecidos. São Paulo: Fonte Comunicações e Editora, 1998.

13 MANO FILHO, A C. Búfalos no Brasil. São Paulo : Associação Brasileira dos Criadores de Búfalo, 1991. $4 \mathrm{p}$.

14 MARTINS, J.F.P.; LOPES, C.N. Doce de leite: aspecto de tecnologia de fabricação. Instruções Técnicas ITAL, Campinas, n. 18, p. 1$37,1981$.

15 MELO, B.D.G.F.; LANDGRAF, M. Microbiologia dos alimentos. 2. ed. São Paulo: Atheneu, 1996.

16 CARVALHO, L.O.D.M.; LOURENÇO JUNIOR, J.B.; TEIXEIRA NETO, J.F. Programa de soerguimento da bubalinocultura no Estado do Pará. Belém: Associação Paraense de Criadores de Búfalos, 1997. $8 \mathrm{p}$. 
17 SILVA JR., E.A. Manual de controle higiênico-sanitário em alimentos. 2.ed. São Paulo: Varela, 1996.

18 VANDERZANT, C.; SPLTTSTOESSER, D. F. Compendium of methods for microbiological examination of foods. $3^{\text {rd }}$ ed. Washington, DC: American Public Health Association, 1992. $914 \mathrm{p}$.

19 VERRUMA, M.R.; SALGADO, J.M.; OLIVEIRA, A.J. Avaliação química e nutricional do queijo Mozzarella e iogurte de leite de búfala. Scientia Agrícola, v. 50, n. 3, p. 438-443, 1993. 